\title{
A Comparison of the Bridge-type ROI-C Interbody Fusion Cage System and Titanium Mesh Graft With Titanium Plate Fixation in 2-level Anterior Cervical Discectomy and Fusion With Plating and Cage System: A Retrospective Study
}

Shuangjun He

The First Affiliated Hospital of Soochow University

Zhangzhe Zhou

The First Affiliated Hospital of Soochow University

Xiaofeng Shao

The First Affiliated Hospital of Soochow University

Changhao Zhang

The First Affiliated Hospital of Soochow University

Xinfeng Zhou

The First Affiliated Hospital of Soochow University

Shuhua Wu

The People's Hospital of Danyang

Kangwu Chen

The First Affiliated Hospital of Soochow University

Yaowei Wang

The People's Hospital of Danyang

Zhonglai Qian ( $\square$ qzldoctor@163.com )

First Affiliated Hospital of Soochow University

Research article

Keywords: ACDF, ROI-C, cervical spondylosis

Posted Date: July 28th, 2020

DOI: https://doi.org/10.21203/rs.3.rs-48049/v1

License: (c) (i) This work is licensed under a Creative Commons Attribution 4.0 International License.

Read Full License 


\section{Abstract \\ Objective}

To explore the clinical efficacy and radioactive results of the bridge-type ROI-C interbody fusion cage (ROI-

C) and anterior cervical discectomy and fusion with plating and cage system (ACDF) for cervical spondylopathy.

\section{Methods}

From January 2014 to January 2018, 45 patients undergoing ACDF were retrospectively analyzed, including 24 cases of ROI-C (group A) and 21 cases of ACDF (group B). The operation time, blood loss, Neck Disability Index (NDI), Japanese Orthopaedic Association score (JOA), postoperative complications, imaging results including cervical Cobb angle and fusion were compared between groups.

\section{Results}

All patients were successfully treated with surgery, and no cerebrospinal fluid leakage, esophageal fistula, or hoarseness occurred after surgery. The operation time and blood loss in group $A$ were lower than those in group $B(P<0.05)$. During the follow-up period, JOA score increased and NDI score decreased after operation $(P<0.05)$, but there was no significant difference between the groups $(P>0.05)$. The incidence of dysphagia in group $A$ was lower than that in group $B$ at 1 month and 3 months after operation $(\mathrm{P}<$ 0.05), but the final follow-up results showed that there was no significant difference in the incidence of dysphagia between the two groups $(P>0.05)$. In group $A$, the fusion rate was $83.3 \% 3$ months after surgery and $100 \%$ at the last follow-up. The rate of adjacent level ossification development was $12.5 \%$. In group B, the fusion rate was $85.7 \% 3$ months after surgery and $100 \%$ at the last follow-up. The rate of adjacent level ossification development was $23.8 \%$.

\section{Conclusion}

Both ROI-C and ACDF can achieve satisfactory results, but ROI-C has shorter operation time, less bleeding and lower incidence of dysphagia in the short term.

\section{Introduction}

Cervical spondylosis is a common clinical degenerative disease. With the change of people's lifestyles, the incidence of cervical spondylosis increases year by year ${ }^{[1]}$. Spinal cord dysfunction caused by cervical spondylosis seriously affects the quality of life of patients ${ }^{[2]}$. With the continuous improvement of medical technology and medical equipment, surgical treatment methods for cervical spondylopathy 
are becoming more and more diverse, including anterior discectomy and fusion internal fixation and posterior laminectomy or plastic surgery. Anterior cervical surgery is accepted by more and more patients due to its small trauma, fast recovery and definite curative effect ${ }^{[3,4]}$. ACDF is often used in the operation of 2-level cervical spondylosis. This operation has been proved to be an effective treatment method, but there are still some complications. It was reported that the complications are common such as

dysphagia, esophageal injury, bone nonunion, screw loosening and plate displacement ${ }^{[5,6]}$. Therefore, how to reduce postoperative complications on the premise of adequate decompression, firm fixation and bone graft fusion has been an important research direction in the treatment of cervical spondylosis.

ROI-C, a new surgery, that is composed of PEEK box and two self-locking clips has been successfully applied in clinical practice, which provide a stable biomechanical environment and avoid the implant contact with the anterior vertebral soft tissue. In this study, 45 patients with cervical spondylosis were retrospectively analyzed. We compared the curative effect and complications of patients with cervical spondylosis treated with the bridge-type ROI-C interbody fusion cage system and titanium mesh graft with titanium plate fixation.

\section{Materials And Methods}

General information

From January 2014 to January 2018, there were 24 patients in ROI-C group (group A), including 9 males and 15 females, aged 51-71 (60.59 \pm 8.21) years old; 21 patients in ACDF group (group B), including 8 males and 13 females, aged 52-70 (60.15 \pm 7.52$)$ years old. The inclusion criteria were as follows: $(1)$ cervical spondylosis showed corresponding symptoms, such as neck and shoulder pain, numbness, limb weakness, walking instability, cotton feeling and other symptoms; (2) cervical X-ray film, computed tomography (CT) or magnetic resonance imaging (MRI) showed compression of adjacent 2-level spinal cord or nerve root. Exclusion criteria included: (1) developmental stenosis and ossification of the posterior longitudinal ligament; (2) previous cervical surgery, tumor or any serious disease history; (3) cervical fracture dislocation or severe cervical instability.

Surgical procedures

All operations were performed by two experienced surgeons in the same treatment group. The patients were administered general anesthesia and were placed in the supine position. In the group A, trial spacers were used to determine the appropriate size of the anchored intervertebral fusion cage. After implantation of the cage, two cervical anchoring clips were placed into the lower and upper vertebrae through the anterior part of the cage to ensure primary stabilization by self-locking function of the anchoring clips. In the group $B$, the appropriate size for the cage was determined by intraoperative evaluation using a trial cage $\llbracket$ Self-tapping screws were used to fix the anterior cervical plate.

Clinical evaluation 
Record the operation time, the bleeding during the operation, and observe the postoperative complications, including the incidence of dysphagia, the duration of symptoms and whether they are disappeared. JOA score ${ }^{[7]}$ and NDI score ${ }^{[8]}$ were used to evaluate the clinical outcomes before and after surgery. The effect of operation was determined by Odom's score ${ }^{[9]}$, and its grades were as follows: excellent, symptoms and signs disappeared after operation; good, most symptoms and signs were relieved and normal function was restored; generally, symptoms and signs were partially improved, but could not operate normally; poor, symptoms and signs were basically the same as before operation. According to the Bazaz score ${ }^{[10]}$, the degree of dysphagia was divided into four grades: none, no dysphagia; mild, almost no dysphagia; moderate, occasional dysphagia; severe, severe dysphagia.

Radioactivity evaluation

The imaging data included preoperative and postoperative imaging examination. If all the following conditions are satisfied, it is considered that radiologic fusion is achieved:

a) The displacement of adjacent vertebrae $<2^{\circ}$ in flexion and extension of neck; b) height of the intervertebral space was unchanged; c) no transparent line was seen between the grafted bone and the upper and lower endplates of vertebral body. The evaluation criteria of adjacent level ossification development (ALOD) were as follows: grade 0 (no ALOD formation), grade 1 (ALOD extends across less than $50 \%$ of the disc space), grade 2 (ALOD extends greater than or equal to $50 \%$ of the disc space), and grade 3 (complete bridging of the adjacent discspace). The cobb angle is measured in the sagittal position of the cervical spine, which is formed between the perpendicular line of the inferior end plate of the $\mathrm{C} 2$ and $\mathrm{C} 7$ vertebral body.

Statistical treatment.

All statistical analyses were performed using SPSS 19.0 software (SPSS Inc., Chicago, USA). Student t test was used to analyze the clinical and radiological outcomes among both groups. Chi square test was used to assess rate of dysphagia, ALOD and fusion. All $P<0.05$ values were considered statistically significant.

\section{Results}

Clinical evaluation

All patients were successfully treated with surgery, and no cerebrospinal fluid leakage, esophageal fistula, or hoarseness occurred after surgery. The 45 patients were divided into 2 groups: Group A (24 patients), who underwent fusion using ROI-C (Figs. 1 and 2); and Group B (21 patients), who underwent fusion using ACDF (Figs. 3 and 4). In group A, the patient was $60.59 \pm 8.21$ years old, the follow-up time was $25.6 \pm 3.3$ months, the operation time was $101 \pm 22 \mathrm{~min}$ and blood loss was $150 \pm 46 \mathrm{ml}$ (Table 1). JOA score increased from preoperative $9.6 \pm 1.7$ to postoperative $13.8 \pm 2.2$, and finally maintained at $14.5 \pm$ 1.5. NDI score decreased from preoperative $32.1 \pm 7.9$ to postoperative $15.9 \pm 4.7$, and finally maintained 
at $13.7 \pm 4.6$ (Table 2). One month after surgery, 3 patients had complications of dysphagia, but the symptom soon disappeared (Table 3 ). In group $B$, the patient was $60.15 \pm 7.52$ years old, the follow-up time was $26.1 \pm 3.5$ months, the operation time was $118 \pm 29$ min and blood loss was $185 \pm 58 \mathrm{ml}$ (Table 1). JOA score increased from preoperative $9.4 \pm 1.5$ to postoperative $14.1 \pm 1.6$, and finally maintained at $14.6 \pm 1.8$. NDI score decreased from preoperative $30.5 \pm 8.6$ to postoperative $15.1 \pm 4.9$, and finally maintained at $13.1 \pm 4.4$ (Table 2). One month after the operation, 8 patients had dysphagia complications, of which 4 patients disappeared at 3 months after operation, and one patient still had dysphagia at the last follow-up (Table 3). The operation time and blood loss in group A were lower than those in group $B(P<0.05)$. During the follow-up period, JOA score increased and NDI score decreased after operation $(P<0.05)$, but there was no significant difference between the groups $(P>0.05)$. The incidence of dysphagia in group $A$ was lower than that in group $B$ at 1 month and 3 months after operation $(P<0.05)$, but the final follow-up results showed that there was no significant difference in the incidence of dysphagia between the two groups $(P>0.05)$.

Table 1

General information

\begin{tabular}{|llll|}
\hline & Group A & Group B & Pvalue \\
\hline Number & 24 & 21 & \\
\hline Gender & & & \\
\hline Male & 9 & 8 & \\
\hline Female & 15 & 13 & 0.853 \\
\hline Age (year) & $60.59 \pm 8.21$ & $60.15 \pm 7.52$ & 0.625 \\
\hline Follow-up (months) & $25.6 \pm 3.3$ & $26.1 \pm 3.5$ & 0.031 \\
\hline Operation time (minute) & $101 \pm 22$ & $118 \pm 29$ & 0.029 \\
\hline Blood loss (ml) & $150 \pm 46$ & $185 \pm 58$ & \\
\hline$P$ value is given for comparison between group A and group B & & \\
\hline$P<0.05$, statistically significant. & & \\
\hline
\end{tabular}


Table 2

Clinical and radiologic data evaluated before surgery and during follow-up (mean $\pm \mathrm{SD}$ )

\begin{tabular}{|c|c|c|c|}
\hline & Group A & Group B & $P$ value \\
\hline \multicolumn{4}{|l|}{ JOA scores } \\
\hline Preoperatvie & $9.6 \pm 1.7^{a}$ & $9.4 \pm 1.5^{\mathrm{a}}$ & 0.680 \\
\hline Postoperative 1 month & $13.8 \pm 2.2^{b}$ & $14.1 \pm 1.6^{b}$ & 0.608 \\
\hline Last follow-up & $14.5 \pm 1.5^{\mathrm{b}}$ & $14.6 \pm 1.8^{b}$ & 0.840 \\
\hline \multicolumn{4}{|l|}{ NDI scores } \\
\hline Preoperatvie & $32.1 \pm 7.9^{a}$ & $30.5 \pm 8.6^{a}$ & 0.519 \\
\hline Postoperative 1 month & $15.9 \pm 4.7^{b}$ & $15.1 \pm 4.9^{b}$ & 0.579 \\
\hline Last follow-up & $13.7 \pm 4.6^{b}$ & $13.1 \pm 4.4^{b}$ & 0.658 \\
\hline \multicolumn{4}{|c|}{ JOA Japanese Orthopedic Association, NDINeck Disability Index } \\
\hline \multicolumn{4}{|c|}{${ }^{a} \mathrm{P}$ value is given for comparison between group $A$ and group $B$} \\
\hline
\end{tabular}

Table 3

Incidence of dysphagia.

\begin{tabular}{|llll|}
\hline & Group A & Group B & $P$ value \\
\hline Dysphagia & $12.5 \%(3 / 24)$ & $38.1 \%(8 / 21)$ & 0.046 \\
\hline One month postoperatively & $0 \%(0 / 24)$ & $19 \%(4 / 21)$ & 0.025 \\
\hline Final follow-up & $0 \%(0 / 24)$ & $4.8 \%(1 / 21)$ & 0.280 \\
\hline$P$ value is given for comparison between group A and group B \\
\hline$P<0.05$, statistically significant. \\
\hline
\end{tabular}

Radioactivity evaluation

In group $A$, cobb angle increased from preoperative $13.5 \pm 10.3$ to postoperative $18.9 \pm 9.4$, and finally maintained at $17.9 \pm 9.8$. The fusion rate was $83.3 \% 3$ months after surgery and $100 \%$ at the last followup. The rate of adjacent level ossification development was $12.5 \%$. In group B, cobb angle increased from preoperative $12.5 \pm 9.4$ to postoperative $17.5 \pm 10.4$, and finally maintained at $17.1 \pm 10.6$. The fusion rate 
was $85.7 \% 3$ months after surgery and $100 \%$ at the last follow-up. The rate of adjacent level ossification development was $23.8 \%$ (Table 4).

Table 4

The mean outcomes of radiological parameters measured before operation and during follow-up(mean \pm SD)

\begin{tabular}{|c|c|c|c|}
\hline & Group A & Group B & $P$ value \\
\hline \multicolumn{4}{|l|}{ Cervical lordosis } \\
\hline Preoperatvie & $13.5 \pm 10.3^{a}$ & $12.5 \pm 9.4^{a}$ & 0.737 \\
\hline Postoperative 1 month & $18.9 \pm 9.4^{b}$ & $17.5 \pm 10.4^{b}$ & 0.638 \\
\hline Last follow-up & $17.9 \pm 9.8^{b}$ & $17.1 \pm 10.6^{b}$ & 0.794 \\
\hline \multicolumn{4}{|l|}{ Fusion rate } \\
\hline Postoperative 3 month & $83.3 \%(20 / 24)$ & $85.7 \%(18 / 21)$ & 0.826 \\
\hline Final fusion & $100 \%$ & $100 \%$ & \\
\hline Adjacent segment degeneration & $12.5 \%(3 / 24)$ & $23.8 \%(5 / 21)$ & 0.322 \\
\hline \multicolumn{4}{|c|}{ a $P$ value is given for comparison between group $A$ and group $B$} \\
\hline${ }^{b} \mathrm{P}<0.05$ comparing with preor & tive value & & \\
\hline
\end{tabular}

\section{Discussion}

After conservative treatment was ineffective, surgical intervention became the first choice ${ }^{[11]}$. ACDF is the standard surgery for the treatment of cervical degenerative disc disease, which can restore the physiological radian of cervical vertebra to the maximum extent, have high intervertebral fusion rate, maintain the stability of cervical spine, and have remarkable surgical effect ${ }^{[12]}$. In our study, the postoperative cervical cobb angle of the two surgery was significantly bigger than the preoperative cervical cobb angle, which indicated that both surgery can correct cervical kyphosis. Therefore, the fusion and biomechanical stability of ROI-C are equal to those of ACDF, and satisfactory surgical results of both surgery have been achieved ${ }^{[13]}$. The results of this study showed that JOA score and NDI score of both groups were improved, and good operation effect was maintained during the follow-up period, which demonstrated that the two surgery can relieve spinal cord and nerve compression, and improve the quality of life of patients.

This study found that the ROI-C has the following advantages: 1 . The operation wound is smaller and less bleeding. Although ROI-C surgery can't reduce skin incision, it is not necessary to consider the placement of plate fixation and extensive exposure of adjacent vertebral body, only need to expose the target intervertebral space, which is convenient for operation. 2 . The operation time is relatively short and 
the operation is simple. In group A, the cage was directly fixed with self-locking clip, which could save operation time. 3. The incidence of dysphagia was reduced after operation. At present, dysphagia is a common complication after ACDF, whose mechanism has not been explained clearly ${ }^{[14,15]}$. It may be related to the following factors: 1 . During anesthesia, the stimulation of pharynx and trachea may cause dysphagia. Some scholars suggest that atomization after operation can partly relieve dysphagia symptoms. Dysphagia caused by this reason can be recovered within one month. 2. Postoperative soft tissue adhesion may lead to dysphagia. In order to expose the target position, the soft tissue in front of the vertebral body needs to be stripped. In group $A$, only the intervertebral space needs to be exposed to facilitate the operation, while in group $B$, the plate fixation is placed in front of the vertebral body, resulting in a wider range of exposure and more bleeding, which increased the possibility of postoperative adhesion. 3.The incidence of dysphagia will be increased by using anterior cervical plate ${ }^{[16]}$. A large number of clinical studies have shown that after plate fixation is fixed, the plate will protrude from the surface of cervical body, which cause slight compression on the esophagus ${ }^{[17,18]}$. Some scholars reported that the use of thinner plate fixation will reduce the incidence of dysphagia ${ }^{[19]}$. Previous studies have also shown that the use of zero-profile anchored spacer can significantly reduce the incidence of dysphagia. In this study, we found that the ROI-C was completely implanted in the intervertebral space, and there was no compression on the esophagus. The incidence of dysphagia in group A was lower than that in group B. the difference was statistically significant at one month and three months after operation, which indicated that the use of ROI-C can reduce the incidence of early dysphagia.

The effect of ACDF depends on the degree of decompression, the recovery of cervical lordosis and the stability of fusion. Anterior plate fixation is often used in ACDF to improve the speed of interbody fusion and enhance the stability of cage. Only after bone fusion can kyphosis and spinal canal stenosis be effectively prevented, so as to prevent compression of spinal cord and nerve root ${ }^{[20]}$. Wang et al. ${ }^{[21]}$ and Grasso et al. ${ }^{\text {[2] }}$ reported a fusion rate of $100 \%$ in patients with ROI-C who were followed up for 2 years. Hofstetter et al. ${ }^{[12]}$ reported that the fusion rate of ROI-C was $95.2 \%$ after an average follow-up of 13.9 months. Our results show that the two groups have achieved satisfactory results of bone fusion, and there is no significant difference between the two methods.

So far, the mechanism of adjacent joint degeneration is not clear. It is not only related to the natural degradation of adjacent joints, but also to the increase of adjacent upper and lower joint activities caused by abnormal fusion ${ }^{[23,24]}$. Lee et al. ${ }^{[25]}$ believe that the use of short plates with oblique screw tracks can significantly reduce the incidence and severity of ALOD. Many studies have shown that the shorter the plate length, the lower the incidence of ossification of the adjacent vertebral body, which may be related to the separation of the soft tissue in front of the vertebral body ${ }^{26,27]}$. In group A, 3 patients had adjacent vertebral degeneration, and 5 patients in group $B$ had adjacent vertebral degeneration. In the last followup, no patient needed surgical intervention. In the future, we will continue to investigate and further evaluate whether the bridge-type ROI-C interbody fusion cage can help reduce the incidence of adjacent vertebral degeneration and the need for reoperation. 
Of course, this study also has some limitations: first of all, this study is a retrospective study, and the level of evidence is limited. Secondly, there may be measurement errors. In order to minimize these errors, three orthopedic surgeons measured the X-ray data separately. Finally, the number of cases in this study is small and the follow-up time is short, which may lead to selective bias. In the future, robust randomized multi-center prospective studies with long-term follow-up are needed to confirm these findings.

\section{Conclusion}

Both ROI-C and ACDF can achieve satisfactory results, but ROI-C has shorter operation time, less bleeding and lower incidence of dysphagia in the short term.

\section{Abbreviations}

\section{ROI-C}

the bridge-type ROI-C interbody fusion cage; ACDF:anterior cervical discectomy and fusion with plating and cage system; JOA:Japanese Orthopaedic Association score; NDI:Neck Disability Index; ALOD:adjacent level ossification development; MRI:magnetic resonance imaging; CT:computed tomography

\section{Declarations}

\section{Funding}

This work was supported by the National NatureScience Foundation of China (grant no. 81802682) and the Natural Science Foundation of JiangsuProvince (grant no. BK20180199).

\section{Availability of data and materials}

The datasets used and/or analysed during the current study are available from the corresponding author on reasonable request

\section{Authors' contributions}

All authors made substantive intellectual contributions to this study to qualify as authors. QZ, WY and CK contributed to study design, acquisition of data, analysis of data, and interpretation of results. ZC and ZX contributed to study coordination. SX, ZC and WS contributed to statistical analysis. HS and ZZcontributed to manuscript preparation. All authors read and approved the final manuscript.

\section{Ethics approval and consent to participate}

This study was approved by the Institutional Ethics Committee of Soochow University. Written informed consent was obtained from all participants. 


\section{Competing interests}

The authors declare that they have no competing interests.

\section{Consent for publication}

Springer Nature remains neutral with regard to jurisdictional claims in published maps and institutional affiliations.

\section{Acknowledgements}

Thanks to the support from the First Affiliated Hospital of Soochow University.

\section{References}

1. Boogaarts HD, Bartels RH. Prevalence of cervical spondylotic myelopathy. Eur Spine J. 2015;24(Suppl 2):139-41.

2. Matsunaga S, Komiya S, Toyama Y. Risk factors for development of myelopathy in patients with cervical spondylotic cord compression. Eur Spine J. 2015;24(Suppl 2):142-9.

3. De la Garza-Ramos R, Xu R, Ramhmdani S, et al. Long-term clinical outcomes following 3- and 4-level anterior cervical discectomy and fusion. J Neurosurg Spine. 2016;24(6):885-91.

4. Epstein NE, Hollingsworth R. Diagnosis and management of traumatic cervical central spinal cord injury: A review. Surg Neurol Int. 2015;6(Suppl 4):140-53.

5. Arnold PM, Anderson KK, Selim A, et al. Heterotopic ossification following single-level anterior cervical discectomy and fusion: results from the prospective, multicenter, historically controlled trial comparing allograft to an optimized dose of rhBMP-2. J Neurosurg Spine. 2016;25(3):292-302.

6. Lee $\mathrm{CH}$, Lee J, Kang JD, et al. Laminoplasty versus laminectomy and fusion for multilevel cervical myelopathy: a meta-analysis of clinical and radiological outcomes. J Neurosurg Spine. 2015;22(6):589-95.

7. Yonenobu K, Abumi K, Nagata K, Taketomi E, Ueyama K. Interobserver and intraobserver reliability of the Japanese orthopaedic association scoring system for evaluation of cervical compression myelopathy. Spine. 2001;26(17):1890-4.

8. Vernon H, Mior S. The Neck Disability Index: a study of reliability and validity. J Manipulative Physiol Ther. 1991;14(7):409-15.

9. Odom GL, Finney W, Woodhall B. Cervical disk lesions. J Am Med Assoc. 1958;166(1):23-8.

10. Bazaz R, Lee MJ, Yoo JU. Incidence of dysphagia after anterior cervical spine surgery: a prospective study. Spine. 2002;27(22):2453-8.

11. Li J, Zheng Q, Guo X, et al. Anterior surgical options for the treatment of cervical spondylotic myelopathy in a long-term follow-up study. Arch Orthop Trauma Surg. 2013;133(6):745-51. 
12. Hofstetter CP, Kesavabhotla K, Boockvar JA. Zero-Profile Anchored Spacer Reduces Rate of Dysphagia Compared with ACDF with Anterior Plating. J Spinal Disord Tech. 2015;28(5):E284-90.

13. Bucci MN, Scott Cowan DOh,R, et al. The ROI-C Zero-Profile Anchored Spacer for Anterior Cervical Discectomy and Fusion: Biomechanical Profile and Clinical Outcomes. Med Devices (Auckl). 2017 Apr 18(10)61-69.

14. Nguyen C, Sanchez K, Roren A, et al. Anatomical specificities of the degenerated cervical spine: a narrative review of clinical implications, with special focus on targeted spinal injections. Ann Phys Rehabil Med. 2016.

15. Nakagawa H, Okazaki T, Saito K. Surgical Strategies in Management of Cervical Spondylotic Myelopathy. World Neurosurg. 2015;84(2):220-1.

16. Shin JS, Oh SH, Cho PG. Surgical outcome of a Zero-profile device comparing with stand-alone cage and anterior cervical plate with iliac bone graft in the anterior cervical discectomy and fusion [J]. Korean J Spine. 2017;11(3):169-77.

17. Chung JY, Kim SK, Jung ST, et al. Clinical adjacentsegment pathology after anterior cervical discectomy and fusion: results after a minimum of 10-year follow-up [J]. Spine J. 2014;14(10):22908. DOI:10.1016/j.spine.2014.01.027.

18. Chen Y, Chen H, Cao P, et al. Anterior cervical interbody fusion with the Zero-P spacer: mid-term results of two-level fusion. Eur Spine J. 2015;24(8):1666-72.

19. Alimi M, Njoku I, Hofstetter CP, et al. Anterior cervical discectomy and fusion (ACDF): comparison between Zero Profile implants and anterior cervical plate and spacer [J]. Cureus. 2016;8(4):e573e580.

20. Kaiser MG, Haid RW Jr, Subach BR, Barnes B, Rodts GE Jr. Anterior cervical plating enhances arthrodesis after discectomy and fusion with cortical allograft. Neurosurgery. 2002;50:229-36.

21. Wang Z, Jiang W, Li X, et al. The application of zero-profile anchored spacer in anterior cervical discectomy and fusion. Eur Spine J. 2015;24:148-54.

22. Grasso G, Giambartino F, Tomasello G, lacopino G. Anterior cervical discectomy and fusion with ROIC PEEK cage: cervical alignment and patient outcomes. Eur Spine J. 2014;23(Suppl 6):650-7.

23. Goodwin CR, Desai A, Khattab MH, et al. Cervical Fusion for Absent Pedicle Syndrome Manifesting with Myelopathy. World Neurosurg. 2016;86:515. e17-22.

24. He L, Qian Y, Jin YJ, et al. [The clinical value of end plate rings in preventing subsidence of titanium cage in anterior cervical corpectomy and fusion surgery]. Zhongguo Gu Shang. 2014;27(9):738-44.

25. Lee DH, Lee JS, Yi JS, et al. Anterior cervical plating technique to prevent adjacent-level ossification development. Spine J. 2013;13(7):823-9.

26. Park JB, Cho YS, Riew KD, et al. Development of adjacent- level ossification in patients with an anterior cervical plate. J Bone Joint Surg Am. 2005;87:558-63.

27. Ishihara $H$, Kanamori $M$, Kawaguchi $Y$, et al. Adjacent segment disease after anterior cervical interbody fusion. Spine J. 2004;4(6):624-8. 


\section{Figures}
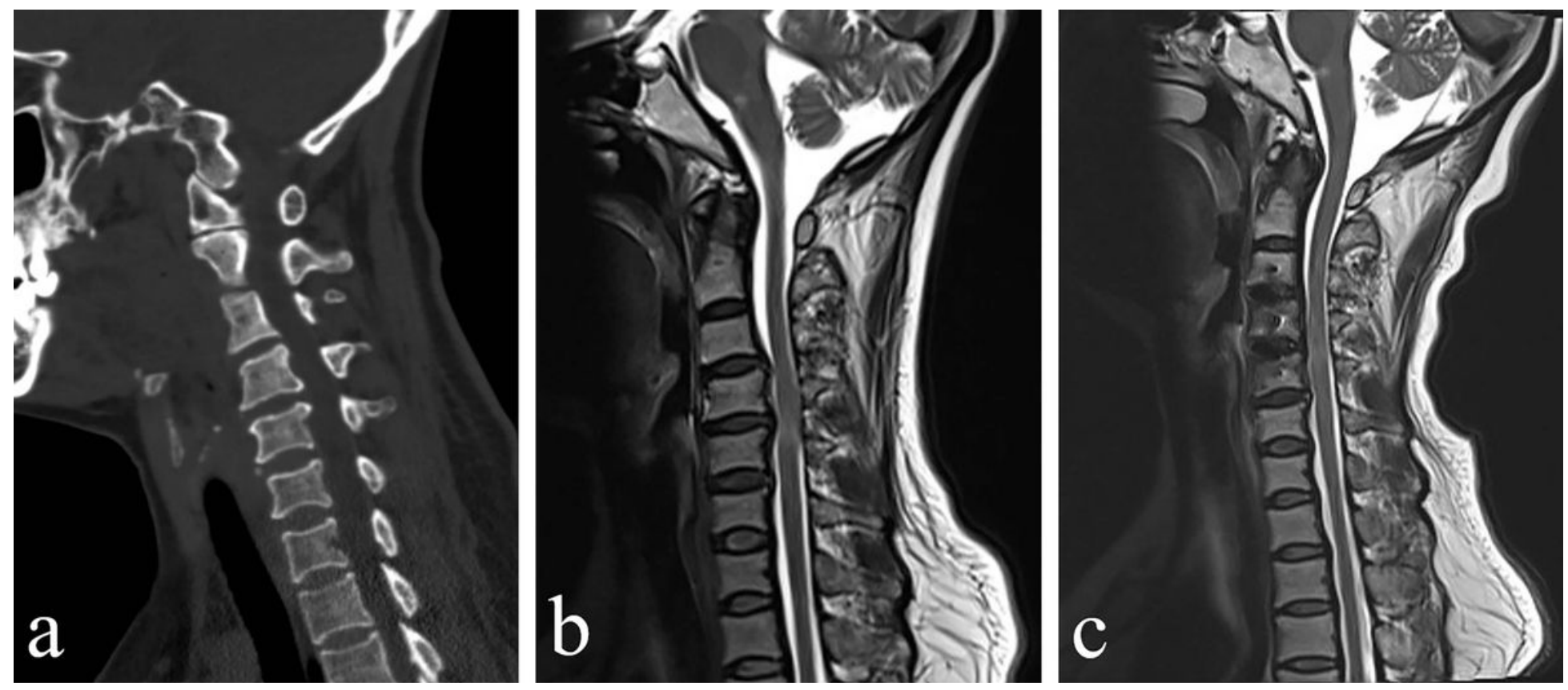

Figure 1

A 65-year-old woman with cervical spondylosis was admitted to our hospital due to numbness and weakness of both upper limbs: (a) Preoperative CT showed cervical degeneration, loss of physiological radian and hyperosteogeny; (b) Preoperative MRI indicated C3-C4 and C4-C5 cervical disc herniation and spinal cord compression; (c) Postoperative MRI noted that the spinal cord compression and the symptoms were relieved.
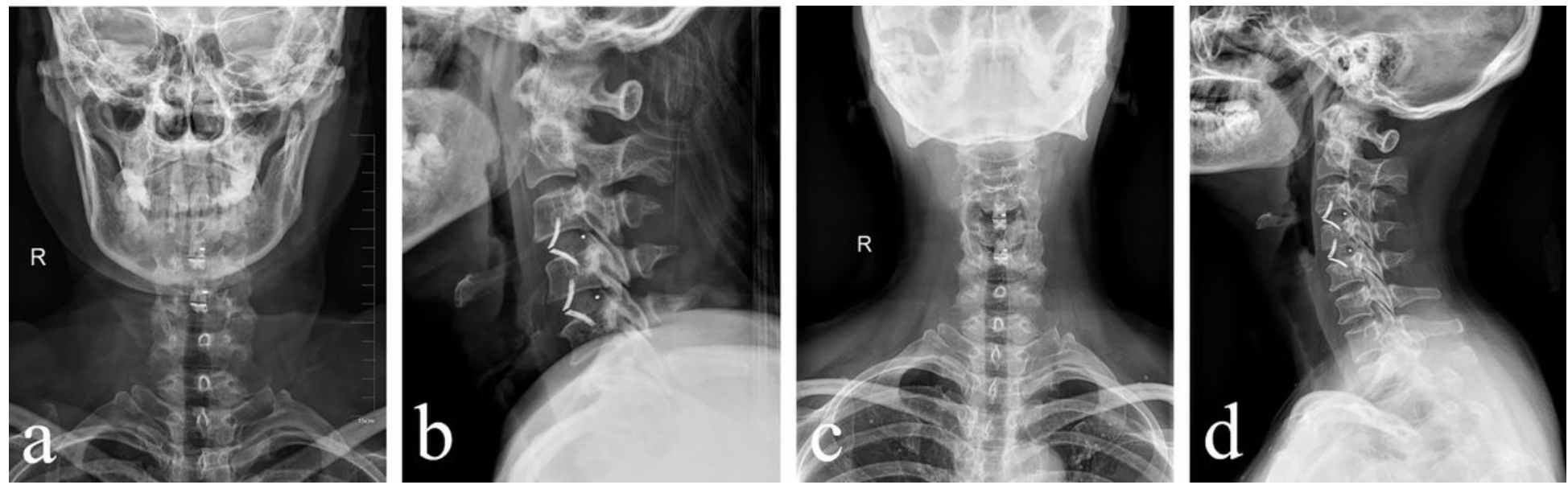

Figure 2

$(\mathrm{a}, \mathrm{b})$ Three days after operation, X-ray showed that C3-C4 and C4-C5cervical discectomyand the positions of bridge-type ROI-C interbody fusion cages were good; (c, d) One year after operation, X-ray showed that $\mathrm{C} 3-\mathrm{C} 4$ and $\mathrm{C} 4-\mathrm{C} 5$ cervical fusion and the positions of bridge-type ROI-C interbody fusion cages were good. 

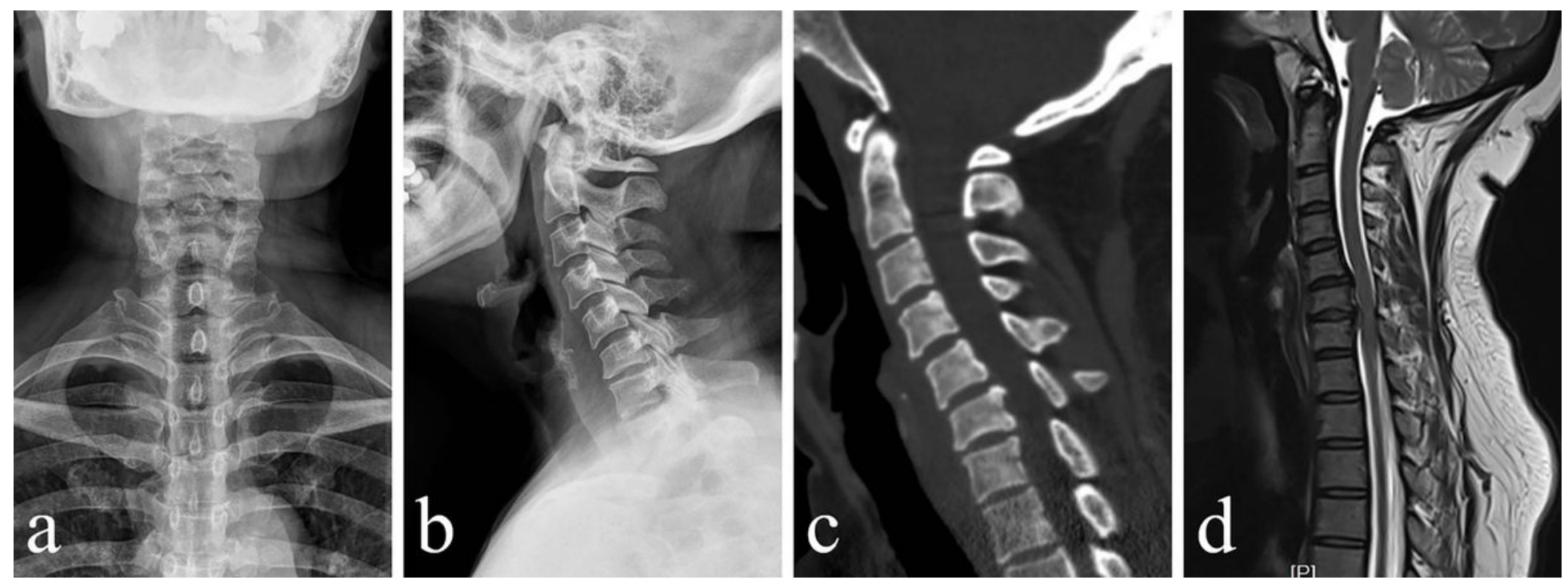

Figure 3

$(a, b)$ Preoperative $\mathrm{X}$-ray showed the disappearance of cervical vertebrae radian and hyperosteogeny; (c) Preoperative CT scan showed the disappearance of cervical vertebrae radian and the change of intervertebral space; (d) Preoperative MRI showed C5-C6 and C6-C7 cervical disc herniation and spinal cord compression.
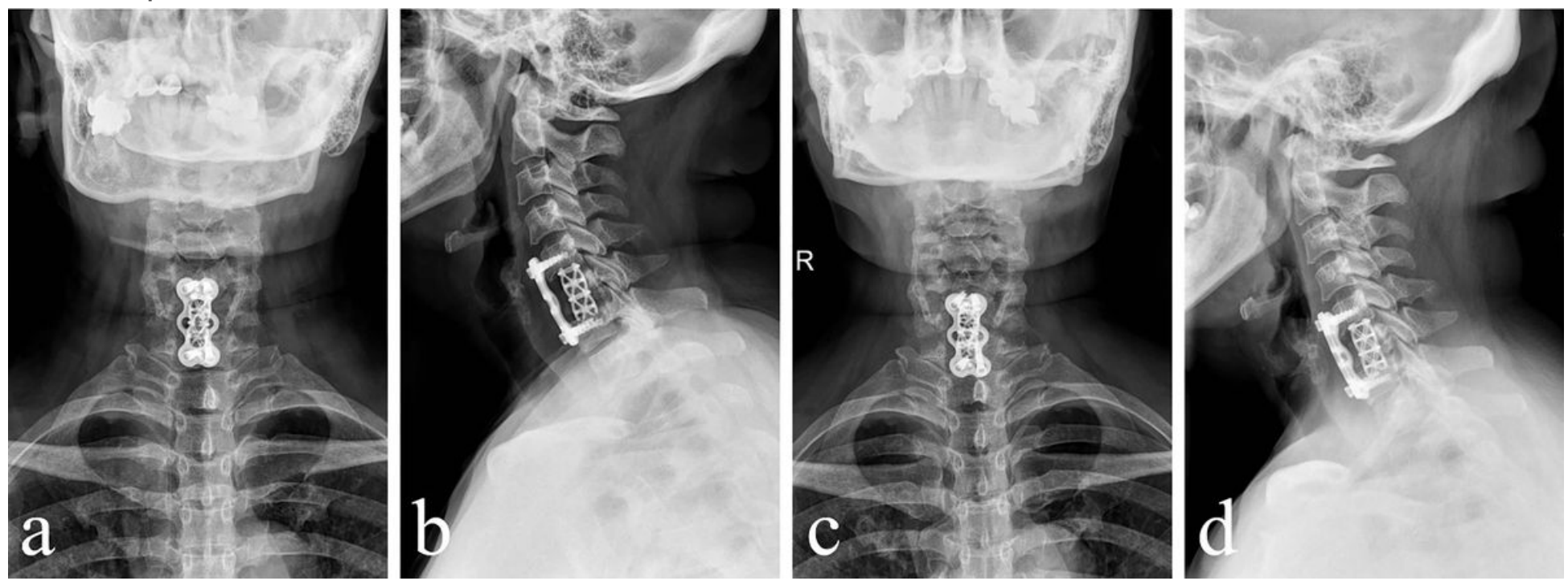

Figure 4

$(\mathrm{a}, \mathrm{b})$ Three days after operation, X-ray showed that C5-C6 and C6-C7cervical discectomy and the positions of titanium mesh and plate were good. (c, d) One year after operation, X-ray showed that C5-C6 and C6-C7cervical fusion and the positions of titanium mesh and plate were good. 